\title{
Burnt in Your Memory or Burnt Memory? Ethical Issues with Optogenetics for Memory Modification
}

\author{
Frederic Gilbert, Alexander R. Harris, and Michael Kidd
}

\section{QUERY SHEET}

This page lists questions we have about your paper. The numbers displayed at left are hyperlinked to the location of the query in your paper.

The title and author names are listed on this sheet as they will be published, both on your paper and on the Table of Contents. Please review and ensure the information is correct and advise us if any changes need to be made. In addition, please review your paper as a whole for typographical and essential corrections.

Your PDF proof has been enabled so that you can comment on the proof directly using Adobe Acrobat. For further information on marking corrections using Acrobat, please visit http://journalauthors.tandf.co.uk/production/acrobat.asp; https://authorservices.taylorandfrancis.com/how-to-correct-proofs-with-adobe/

The CrossRef database (www.crossref.org/) has been used to validate the references.

\section{AUTHOR QUERIES}

Q1 Please resupply the corresponding author details and email address if it is inaccurate.

Q2 Please provide the complete details for the "Clinicaltrials.gov 2020" references list entry.

Q3 The reference "Gilbert et al. 2019" is listed in the references list but is not cited in the text. Please either cite the reference or remove it from the references list.

Q4 Please provide names of all authors, as per journal style for reference 'Wissam et al. 2019" references list entry.

Q5 Please note that the ORCID section has been created from information supplied with your manuscript submission/CATS. Please correct if this is inaccurate. 


\section{Burnt in Your Memory or Burnt Memory? Ethical Issues with Optogenetics for Memory Modification}

Q5 Frederic Gilbert ${ }^{\mathrm{a}} \mathbb{D}$, Alexander R. Harris ${ }^{\mathrm{b}}$, and Michael Kidd ${ }^{\mathrm{a}}$

aUniversity of Tasmania; ${ }^{b}$ University of Melbourne

\section{INTRODUCTION}

In their forthcoming article entitled "Personality and authenticity in light of memory-modifying potential of optogenetics," Zawadzki and Adamczyk explore potential threats associated with futuristic usage of optogenetics for memory modifications. Overall, we agree with the authors' valuable conclusion that contemporary scientific knowledge does not permit knowing how values, traits, behaviors and self-narrative of a person would change under the precise and selective memory modification of optogenetics, however we believe it is due to distinct reasons. One of the main reasons being that the technology will not work as described by the authors.

In our commentary we critically examine some of the scientific claims made by the authors, and demonstrate the unlikeliness of optogenetics becoming a threat to authenticity because of the very limited therapeutic applicability of the technology in humans, in any foreseeable and far future. The core safety concern with using optogenetics for memory modifications in humans involves genetic modification of an individual, implanting an optrode which would induce severe trauma, and risks of using the device including thermal damage to tissue (Gilbert, Harris, Kapsa 2012, 2014).

\section{BURNT INTO YOUR MEMORY OR BURNT MEMORY?}

When we experience trauma (such as that portrayed to Elizabeth ( $\mathrm{p} \mathrm{12)}$ ), it is often characterized by its indelibility; the saying suggests it is burnt in our memory. The hypothesis that optogenetics has an "extraordinary possibility to repeatedly deactivate and reactivate a specific memory" (p 5), or "optogenetics potential to switch on and off selected memories on demand" ( $p$ 2)) assumes memory works in a "precise" way. However, there is a body of literature showing memories are incredibly malleable and likely not accurate (Shaw and Porter 2015). How can neurotechnology accurately target an inaccurate cognitive phenomenon? Phrasing sentences as if clinicians or neuroscientists had precise control on specific memory contents in human brains call for separating science from science fiction. Like other invasive neurotechnologies such as Deep Brain Stimulation (DBS), it is unlikely that optogenetics can precisely targets specific memory contents, as it seems DBS induced flashbacks rather than controlled accurate replicable memory (Viaña, Bittlinger, Gilbert 2017; Viaña et al. 2017; Wissam et al. 2019). Evidence used by the authors to support the idea of optogenetics precision are examples from animal models. Referencing to optogenetics experiments affecting memory in animals does not make results translatable to humans. Authors mention optogenetics being tested in humans, but both human trials do not involve optrode implantation and are being tested for sensory input to peripheral nerves for retinitis pigmentosa sufferers, a significantly different application than activation of neural circuits in the central nervous system associated with memory (ClinicalTrials.gov Identifier: NCT03326336 and NCT02556736, 2020). Memory modification of the transgenic animals is also made after fear conditioning and activation of specific neural circuits. Fear conditioning of humans is not standard practice and not related to control of specific memories such as Elizabeth's trauma. Targeting episodic memories is far more complicated and not currently possible, we do not know how memories are encoded, so we cannot target individual memories for modification. Even if changing one memory was demonstrated, you cannot control multiple memories as you would need an extremely complex and dynamic implant and neural 
modification, including multiple light sources and wavelengths creating optical patterns throughout the brain controlling different light gated ion channels.

The hypothesis that memory can be turned on and off with light assumes the phenomenal effects of optogenetics are irrevocable or permanents. A temporary memory activation during optical illumination is not permanent removal; the phenomenology of optogenetics is reversible by nature. This is the main safety risk associated with the invasive technology and the reason why optogenetics will unlikely be used to target a complex cellular substrate such as human memory. The substantial corpus of collective knowledge of surgical and material risks associated with electronic implants contains some of the safety risks that arise uniquely from optogenetics. These risks include application of high-intensity light to the brain (photodegradation or heating effects) and the likelihood of the light-emitting device's design damaging brain tissue during usage. The temperature change and potential damage is dependent on light wavelength, power, spread, pulse rate/continuous power, tissue composition, and most importantly distance from the light source to the target cells (Stujenske, Spellman, Gordon 2015). In other terms, continually de/activating precise optogenetially modified cells would not burn remembrance into your memory, rather it would burn your memory!

Also, believing optogenetics can aptly target single cells containing precise memories (aspects of a particular traumatic event for example) suggest it is possible to restore missing memories, as well restore self-defining and self-creative memories that were the subjects of erasure/deactivation ( $p$ 15-16). Given the highly associational nature of memory, how could it be possible even to apply fine-grained editing in principle or in practise without affecting other memory chains? Memory is unlikely reducible to single and precise neurones in humans-let alone specific memory traces which might be altered, "deleted," "edited," etc., yet; the potential science described in the manuscript seems to imply something very close to this. Assuming improved "resolution techniques," would this potentially extend to "editing" parts of memories? If so, could memory "episodes" be selectively edited in a manner roughly analogous to video/audio footage? The authors state: "the features of optogenetics offer the same opportunities as existing MMTs, like modification of certain details of memories" (emphasis added) as well as recalling formerly forgotten infant memories (p.4). Obviously, we are reminded of the Philip K. Dick story: We Can Remember it for you
Wholesale (more popularly known from the two movie iterations of Total Recall). As in this sciencefiction scenario, something resembling the "black box" which is crucial to its plot relies upon a technique which implants artificial memories in the chief protagonists. We believe it is unlikely optogenetics will in a far or near future allow operating human memory in that respect.

\section{CONCLUSION}

167

168

There is an ongoing debate about whether some ethical concerns associated with using optogenetics in humans to target memory belong to the realm of speculative ethics (Adamczyk and Zawadzki 2020; Gilbert and Goddard 2014; Müller and Walter 2014). Our goal was not to single out each relevant claim made about the science of optogenetics by the authors and to check whether they are supported by empirical evidence. After all, part of the captivating mission of Zawadzki and Adamczyk's article is to speculate about philosophical concepts and to indulge in thoughtful enquiry, not necessarily trying to ground their hypothesis in empirical evidence. Instead, our goal was to stress that some of the scientific claims about the potential applicability of optogenetics appear to not accurately reflect the possibility of seeing optogenetic being used in humans to target memory in any close or distant future. Nevertheless, in their article, Zawadzki and Adamczyk have strengthened and interestingly engaged with preexisting thought experiment literatures about the ethics of memory modification technologies (Erler 2011).

\section{ORCID}

Frederic Gilbert (D) http://orcid.org/0000-0003-0524-8649

\section{REFERENCES}

Adamczyk, A. K., and P. Zawadzki. 2020. The memorymodifying potential of optogenetics and the need for neuroethics. NanoEthics 14 (3):207-25. doi:10.1007/ s11569-020-00377-1.

Erler, A. 2011. Does memory modification threaten our authenticity? Neuroethics 4 (3):235-49. doi:10.1007/ s12152-010-9090-4.

Gilbert, F., M. Cook, T. O'Brien, and J. Illes. 2019. Embodiment and estrangement: Results from a First-inHuman "Intelligent BCI" Trial. Science and Engineering Ethics 25 (1):83-96. doi:10.1007/s11948-017-0001-5.

Gilbert, F., and E. Goddard. 2014. Thinking ahead too much: Speculative ethics and implantable brain devices. 
AJOB Neuroscience 5 (1):49-51. doi:10.1080/21507740. 2013.863252.

Gilbert, F., A. R. Harris, and R. M. I. Kapsa. 2014. Controlling brain cells with light: Ethical considerations for optogenetic clinical trials. AJOB Neuroscience 5 (3): 3-11. doi:10.1080/21507740.2014.911213.

Gilbert, F., A. Harris, and R. Kapsa. 2012. Efficacy testing as a primary purpose of phase 1 clinical trials: Is it applicable to first-in-human bionics and optogenetics trials? AJOB Neuroscience 3 (2):20-2. doi:10.1080/21507740. 2012.666323.

Müller, S., and H. Walter. 2014. Neither speculative nor narrow-minded ethics is needed for optogenetics-based DBS in psychiatry and neurology. AJOB Neuroscience 5 (3):12-4. doi:10.1080/21507740.2014.911780.

Shaw, J., and S. Porter. 2015. Constructing rich false memories of committing crime. Psychological Science 26 (3): 291-301. doi:10.1177/0956797614562862.
Stujenske, J. M., S. Spellman, and G. A. Gordon. 2015. Modeling the spatiotemporal dynamics of light and heat propagation for in vivo optogenetics. Cell Reports 12 (3): 525-34. doi:10.1016/j.celrep.2015.06.036.

Viaña, J. N. M., M. Bittlinger, and F. Gilbert. 2017. Ethical considerations for deep brain stimulation trials in patients with early-onset Alzheimer's disease. Journal of Alzheimer's Disease 58 (2):289-301. doi:10.3233/JAD161073.

Viaña, J. N. M., J. C. Vickers, M. J. Cook, and F. Gilbert. 2017. Currents of memory: recent progress, translational challenges, and ethical considerations in fornix deep brain stimulation trials for Alzheimer's disease. Neurobiology of Aging 56:202-10. doi:10.1016/j.neurobiolaging.2017.03.001.

Wissam, et al. 2019. Fornix-region DBS-induced memory flasbacks in AD. New England Journal of Medicine 381:8. 


\section{University Library}

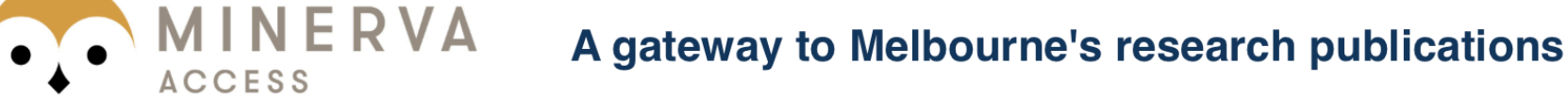

Minerva Access is the Institutional Repository of The University of Melbourne

Author/s:

Gilbert, F;Harris, AR;Kidd, M

Title:

Burnt in Your Memory or Burnt Memory? Ethical Issues with Optogenetics for Memory Modification.

\section{Date:}

2021-01

\section{Citation:}

Gilbert, F., Harris, A. R. \& Kidd, M. (2021). Burnt in Your Memory or Burnt Memory? Ethical Issues with Optogenetics for Memory Modification.. AJOB Neurosci, 12 (1), pp.22-24. https://doi.org/10.1080/21507740.2020.1866104.

Persistent Link:

http://hdl.handle.net/11343/274302 